\title{
¡EH, TÚ! ¿POR QUÉ ME TRADUCES CON ECO? LA TRADUCCIÓN DEL MULTILINGÜISMO PARA EL SOPORTE UNIMODAL Y MULTIMODAL DE LA OBRA COCO (2017) ${ }^{1}$
}

\author{
Lorena Hurtado Malillos \\ Universidad de Valladolid \\ lorena.hurtado@uva.es \\ Carmen Cuéllar Lázaro \\ Universidad de Valladolid \\ carmen.cuellar@uva.es
}

\begin{abstract}
RESUMEN: Este artículo presenta un estudio descriptivo-comparativo cuya finalidad es analizar de qué manera influyen los factores receptor y soporte en el tipo de técnicas de tratamiento aplicadas en la traducción de textos con propiedad multilingüe. Para ello, se ha elegido como estudio de caso dos ejemplos de literatura $y$ cine interlingües inglés-español, "Coco" e "In the time of the butterflies" $y$ se ha estudiado la traducción de estas obras a un idioma en el que no existe coincidencia lingüistica con las lenguas de partida, el alemán. Los resultados obtenidos demuestran que la película "Coco", obra con un soporte multimodal y la novela "In the time of the butterflies", obra dirigida a un público adulto transfieren los segmentos originales enunciados en español. Sin embargo, el cuento "Coco" con un soporte monomodal y dirigido a un receptor infantil adapta esta propiedad lingüistica mediante las estrategias de modificación, homogeneización y transferencia más traducción aclarativa (traducción con eco).

PALABRAS CLAVE: multilingüismo, translingüismo, L3, soporte, receptor, literatura infantil y juvenil, Coco.
\end{abstract}

1. Este estudio ha sido realizado en el marco de una estancia de investigación predoctoral en el Grupo de investigación "Translation and Intercultural Transfer"/"Vertaling en Interculturele Transfer (VICT)" de la Universidad KU Leuven, Bélgica, financiada por el programa de ayudas "MOVILIDAD DOCTORANDOS UVa 2019”, según Resolución de 15 de julio de 2019. 


\title{
HEY, YOU! WHY ARE YOU TRANSLATING ME WITH ECHO? THE TRANSLATION OF MULTILINGUALISM FOR THE UNIMODAL AND MULTIMODAL SUPPORT OF COCO (2017)
}

\begin{abstract}
This article presents a descriptive-comparative study whose purpose is to analyse the influence of the reception and support factors in the type of treatment techniques applied for the translation of multilingual texts. To this end, "Coco" and "In the time of the butterflies" have been chosen as case studies and as examples of English-Spanish translingual literature and film. Likewise, the translation of these works into German, a language that bears no linguistic coincidence with the source languages has been studied. The results show that "Coco", a film with a multimodal support and "In the time of the butterflies", a novel that targets an adult audience, transfer the original segments stated in Spanish. However, "Coco", a story with a monomodal support and targeting children adapts this linguistic property through the strategies of modification, homogenization and transference plus a clarifying translation (translation with echo).
\end{abstract}

KEYWORDS: multilingualism, translanguaging, L3, support, audience, children's and young people's literature, Coco.

\section{HÉ, TOI ! POURQUOI ME TRADUIS-TU EN ÉCHO? LA TRADUCTION DU MULTILINGUISME POUR LE SUPPORT UNIMODAL ET MULTIMODAL DU COCO (2017)}

\footnotetext{
RÉSUMÉ: Cet article présente une étude descriptive-comparative visant à analyser comment les facteurs récepteur et support influencent les techniques de traitement appliquées dans la traduction de textes multilingues. À cet effet, deux exemples de littérature et de cinéma translingues anglais-espagnol, "Coco » et " In the time of the butterflies » ont été choisis comme études de cas. La traduction de ces cuvres en allemand, langue qui ne présente pas de coïncidence linguistique avec les langues sources, a été analysée. Les résultats obtenus montrent que le film "Coco ", auvre à support multimodal et le roman "In the time of the butterflies », cuvre destinée à un public adulte transfèrent les segments originaux énoncés en espagnol. Cependant, le conte "Coco " à support monomodal et destiné à un récepteur infantile, adapte cette propriété linguistique au moyen de stratégies de modification, d'homogénéisation et de transfert accompagné d'une traduction explicative (traduction en écho).
} 
¡EH, TÚ! ¿POR QUÉ ME TRADUCES CON ECO? LA TRADUCCIÓN DEL MULTILINGÜISMO...

MOTS CLÉS: multilinguisme, translinguisme, L3, support, récepteur, littérature d'enfance et de jeunesse, Coco.

Recibido: 25/11/2018. Aceptado: 24/03/2019

\section{Introducción}

En sus intervenciones públicas, el equipo creador $^{2}$ de la película Coco (2017), encabezado por sus directores, Lee Unkrich y Adrián Molina, así como la autora de su adaptación literaria, Ángela Cervantes ${ }^{3}$, enfatizan la importancia del carácter multilingüe de la obra no sólo como un medio de expresión lingüística sino como un símbolo y medio de contextualización de una comunidad y realidad transculturales. En este sentido, el equipo cineasta recurrió a un comité especializado de asesores lingüísticos para que evaluaran los diálogos de la película y establecieron como condición que el autor de literatura infantil que asumiese realizar la novelización de la obra debía poseer personalmente dicho trasfondo biográfico bicultural.

Como recoge Jiménez-Carra (2011: 177), fruto de una concienciación cada vez mayor por parte del mundo editorial, la literatura de adultos ya cuenta con algunos ejemplos de literatura multilingüe traducida en la que esta propiedad del

2. En el siguiente artículo del 19 de noviembre de 2017 publicado en el periódico The New York Times, "How Pixar Made Sure 'Coco' Was Culturally Conscious", un miembro del comité lingüístico asesor de la película explicaba de la siguiente manera cuál fue el protocolo seguido a la hora de elaborar unos diálogos que fuesen fieles y culturalmente respetuosos con la forma de habla real de la comunidad mexico-americana: "The Pixar filmmakers behind "Coco" wanted to portray Mexican culture authentically, so it sought the help of more than 30 creative consultants. [...] "The original idea was to have the characters speak only in English with the understanding that they were really speaking in Spanish," said Octavio Solis, a Mexican-American playwright who was a consultant on the film. "But for us, language is binary, and we code-switch from English to Spanish seamlessly" (R. Ugwu, Cine - The New York Times, 19 nov. 2017).

3. En una entrevista concedida a la publicación Dos Mundos, Two Worlds, la autora de textos infantiles Ángela Cervantes habla sobre sus comienzos en la escritura, la elección de escribir literatura translingüe, así como el hecho de que la compañía Pixar la eligiera para ser la autora que llevase a cabo la adaptación a cuento infantil de la película Coco: "When I was a child [...], I was such a bookworm - and I remember very early in life wondering where the books were about kids like me, and my family and friends. [...] Why weren't there books about Mexican-American kids taking on adventures and solving mysteries? [...] The books I'm writing are exactly the types of books I was searching for"/“They were familiar with my first novel, 'Gaby, Lost and Found,' [...] They were also actively seeking out MexicanAmerican authors to work on the project, which I think says a lot for Disney-Pixar's understanding of what true representation means" (S. Jiménez, Comunidad - Dos Mundos, Two Worlds, 7 dic. 2017). 
texto origen es reproducida en el texto meta, entre ellos, la obra de Julia Álvarez o de Junot Díaz.

[...] las editoriales eran proclives hasta hace relativamente poco a solicitar un TM en el que predominara el español neutro y en el que se eliminara de esta forma cualquier problema de compresión que un texto bilingüe pudiera plantear; sin embargo, la conciencia cada vez mayor de que el cambio de código no es una elección caprichosa por parte del autor, sino una muestra más de la cultura de un grupo de individuos y que, además, tiene un significado que trasciende lo puramente lingüístico, ha ayudado a que se empiecen a publicar traducciones que intentan mantener las características del TO en el TM. (Jiménez-Carra 2011: 177)

Sin embargo, cabe plantearse cómo ha abordado la traducción de esta literatura, considerada fuera del canon por desviarse del ideal estándar monolingüe, la literatura infantil, otro campo que al igual que el multilingüe también es considerado como "el jugador fuera del sistema" (the outsider, Hunt 1990: 1) o "la cenicienta" (the cinderella, Shavit 1994: 5) respecto a los principales géneros y áreas temáticas de la literatura y la traducción. Este tipo de literatura posee asimismo un receptor con unas características específicas en cuanto a edad, así como habilidad lectora y de comprensión que también deben ser consideradas. El presente artículo se propone dar respuesta a estas preguntas, mediante el análisis de la traducción y adaptación a un nuevo idioma, en concreto, el alemán, de la obra multilingüe infantil Coco, en sus vertientes literaria y audiovisual, contrastándola con la traducción de la obra multilingüe para adultos, In the time of the butterflies.

\section{Metodología y objetivos del estudio}

El presente estudio emplea como marco de referencia el modelo de análisis traductológico L1-L3 (Corrius y Zabalbeascoa 2011). De acuerdo a la terminología que propone este modelo, el proceso de traducción de un texto multilingüe se compone de una L1, la lengua principal del texto fuente, y una L3, segunda lengua o lenguas empleadas en el texto de partida, que conviven con la L1. Así, en el caso de la obra analizada Coco, multilingüe inglés-español, la L1 del texto sería el inglés y la L3, el español. La denominación L2, por su parte, se utiliza, conservando la nomenclatura estandarizada, para referirse a la lengua meta hacia la que va a realizarse la traducción. Siguiendo esta configuración, las estrategias de traducción posibles para el fenómeno de la tercera lengua que identifican los 
autores son las siguientes: repetir L3TO $\rightarrow$ L3TM (cuando L3TO $\neq$ L2): repetir el fragmento en $\mathrm{L} 3$ del texto origen en el texto meta $(\mathrm{L} 3 \mathrm{TO}=\mathrm{L} 3 \mathrm{TM})$, siempre que no exista coincidencia con la L2 (L3TO $\neq \mathrm{L} 2)$; sustituir L3TO $\rightarrow$ L2 (cuando $\mathrm{L} 3 \mathrm{TO} \neq \mathrm{L} 2$ ) o repetir $\mathrm{L} 3 \mathrm{TO}$ (cuando $\mathrm{L} 3 \mathrm{TO}=\mathrm{L} 2$ ): sustituir la $\mathrm{L} 3$ por la $\mathrm{L} 2$ del texto meta o transferirla cuando ambas coinciden ( $\mathrm{L} 3 \mathrm{TO}=\mathrm{L} 2)$, homogeneizando el segmento en L3 con el resto del texto y quedando L1 y L3 traducidas a la misma lengua meta; sustituir L3TO (cuando $\mathrm{L} 3 \mathrm{TO} \neq \mathrm{L} 2, \mathrm{~L} 3 \mathrm{TO}=\mathrm{L} 2$ ): sustituir la L3 original por otra lengua o variedad lingüística diferente en el texto meta, ya sea para diferenciarla porque L3TO y L2 coinciden (L3TO=L2) o buscando adaptar la relación L1-L3 al nuevo entorno lingüístico de la L2. Esta distribución determina asimismo la elección como caso de estudio de la traducción a un idioma meta, el alemán, en el que no existe coincidencia L3-L2. La elección de un idioma no coincidente nos permite analizar si la L3 se ha mantenido como elemento diferenciado en la traducción. Esto, por el contrario, no sería posible en el caso de un idioma de destino en el que sí existiese dicha coincidencia, como la traducción de una L3 español origen a una L2 español como lengua de destino, donde la L3 quedaría homogeneizada con la lengua base del texto.

Partiendo de este planteamiento, el presente trabajo se propone estudiar la influencia de las variables destinatario y tipo de soporte en el proceso de traducción del fenómeno de la L3 y la alternancia de código. Para ello, el análisis del tratamiento de la L3 español en la traducción del cuento infantil Coco (2017), se comparará a su vez con el tratamiento aplicado a la L3 en In the time of the Butterflies (1994), obra también multilingüe inglés-español pero dirigida a un público objetivo adulto. Por otro lado, se estudiará y comparará con las anteriores la traducción de la película de animación Coco (2017), en sus modalidades de doblaje y subtitulado, como ejemplo de texto que utiliza un soporte audiovisual. Siguiendo el razonamiento previo, la combinación de idiomas examinada en estas obras será de nuevo la traducción al alemán.

El método de estudio propuesto para el análisis del corpus de obras seleccionadas se trata de un estudio descriptivo de tipo mixto, que combina las modalidades cualitativa y cuantitativa. La información sobre las ocurrencias de segmentos en L3 y las estrategias de traducción aplicadas se ha recabado mediante el muestreo de los textos fuente a partir de técnicas de análisis cuantitativo (clasificación y cómputo de datos). Al mismo tiempo, estas ocurrencias se han analizado posteriormente de forma cualitativa. Los resultados obtenidos a partir de este análisis multidestinatario y multisoporte se discuten, comparando cómo las estrategias de traducción utilizadas en cada caso se relacionan y difieren entre sí. 


\section{La literatura infantil y juvenil multilingüe: un fenómeno con idioma propio}

En nuestra propuesta entendemos de forma general la literatura infantil y juvenil (LIJ), siguiendo la definición proporcionada por Oittinen (2000: 61), una de las investigadoras más reconocidas en este ámbito, como aquella literatura concebida con un público objetivo de tipo infantil y juvenil y acogida como tal por este grupo de edad: "Children's literature can be seen either as literature produced and intended for children or as literature read by children" (Oittinen 2000: 61). En concreto, nos parece importante hacer hincapié en la segunda parte de la definición, esto es, la literatura infantil entendida como aquella literatura leída por niños y jóvenes, puesto que en palabras de Hiriart (2004) "hay textos a los que podemos llamar para niños por el simple hecho de que resultan cercanos y disfrutables para las personas de cuatro, ocho o doce años, hayan sido escritos ex profeso para ellos o no" (Hiriart 2004: 24). La línea que separa ambos mundos, literatura de adultos y literatura infantil, tal y como demuestran algunos géneros como el cómic o la novela gráfica, es ambivalente y se encuentra en constante oscilación. Aunque si bien, desde instituciones educativas y editoriales, así como por parte de adultos facilitadores de las obras y el sistema de expectativas de estos se establecen una serie de pautas implícitas que debe cumplir la que busca ser considerada como literatura infantil, el juicio siempre quedará en manos de cada pequeño lector. Estas pautas o directrices implícitas que definen a la literatura infantil y juvenil como conjunto, y que han sido identificadas por investigadores como O’Sullivan (2013), Alvstad (2010) o García de Toro (2013, 2014) son las siguientes: fuerte protagonismo de los elementos visuales y la sonoridad como recursos expresivos, ingenio y originalidad de la temática, adaptación al contexto cognitivo-comunicativo infantil, lenguaje sencillo orientado a los lectores de esta franja de edad, posesión de carácter lúdico y de entretenimiento al mismo tiempo que cumplimiento de una función didáctica $\mathrm{y}$, finalmente, dualidad del receptor. Se trata de textos destinados a ser leídos y visionados al mismo tiempo por niños y adultos acompañantes y que por tanto poseen niveles de significado exclusivos para cada grupo ${ }^{4}$.

En esta enumeración, el aspecto que resulta más decisivo para los propósitos de este estudio y sobre el que se reflexionará en tanto constituye un

4. Zabalbeascoa (2000: 27) propone el modelo de representación de "un fondo blanco con topos negros" para simbolizar las referencias complejas dirigidas al público adulto, que se introducen en el contenido mayoritario más blanco y familiar de las obras infantiles: comentario social, intertextualidad, dobles sentidos, humor sobre temas tabú, etc. 
canal simultáneo de transmisión de información, es el componente visual. Las imágenes e ilustraciones ocupan un lugar destacado en la literatura infantil y juvenil. Dibujos, colores, formas, líneas, espacios, etc. llenan gran parte del contenido de las páginas de estas obras. Para el público que lee el libro, palabras e imágenes se unen para generar una historia completa. La imagen complementa espacios de significado que el texto por sí sólo no alcanza a transmitir o que precisan ser reforzados, y a la inversa. Al mismo tiempo, los lectores deben suplir con su interpretación personal e imaginación los vacíos de contenido que ninguno de estos dos componentes aborda. Es por ello, que algunos autores se refieren a los libros ilustrados como "iconotextos" (Sipe 2011) o "textos con restricción visual" (Chaume 2003 y Martí Ferriol 2003) dada la relación dialógica que se produce entre texto e imagen en este tipo de obras y que va más allá de la suma de las dos partes como elementos independientes. Así, las ilustraciones no sólo servirían como un medio de soporte en textos monolingües, en el caso de textos que alternan varias lenguas, su funcionalidad se ampliaría también potencialmente a actuar como un elemento compensador de significado en los casos de uso de un idioma o de elementos de un idioma con los que el niño o joven lector no se encuentre familiarizado.

Por otra parte, y retomando la propiedad multilingüe como tema vertebrador del estudio, cabe señalar que la manifestación de este fenómeno en textos literarios y audiovisuales no cuenta todavía con una terminología y criterios de definición consolidados y unánimemente aceptados por el conjunto de la comunidad investigadora. Como apunta Wilson (2011) las propuestas de denominación para este tipo de autores son de lo más variado: "writers are [...] variously referred to as multi, hetero-, poly- or translingual writers (also transnational)" (Wilson 2011: 236). De la misma forma el tipo de obras que pueden crearse presentan varias denominaciones y modelos de texto posibles. A continuación, recogemos las distinciones inter- e intratextualidad multilingüe, en el nivel de la obra y la diferenciación espacial del multilingüismo, en el nivel de la disposición de la página. El investigador Kremnitz (2004) diferencia entre multilingüismo intertextual que describe a los autores que usan varias lenguas en la escritura, pero escriben cada obra independiente de manera monolingüe; y multilingüismo intratextual que describe a los autores que realizan una escritura alterna en varias lenguas dentro de un mismo texto. Asimismo, dentro del contexto particular analizado de la LIJ, la investigadora austriaca Eder (2009: 22) acuñó el término libros interlingües, para referirse a aquellos libros con un texto 
único que combina segmentos en diferentes lenguas en su desarrollo por oposición a libros bilingües o multilingües, aquellos que presentan versiones en diferentes lenguas de un mismo texto, si bien con una disposición espacial en la que las distintas lenguas se encuentran claramente diferenciadas. Desde el ámbito de la enseñanza de lenguas se otorga a esta práctica interlingüe un segundo nombre el de translingüismo (translanguaging, García y Flores 2013), denominación que por poseer un uso más extendido será la que se adopte en lo sucesivo en este estudio.

De forma homóloga, ante la voluntad de incluir una o varias L3 o terceras lenguas en el texto literario, al autor se le plantean dos opciones o procedimientos alternativos principales: en un extremo, la señalización de esta lengua respecto al resto del texto circundante como describe Lennon (2010), esto es, la diferenciación tipográfica de los segmentos en L3, mediante la variación del estilo de texto y/o inclusión de traducciones aclarativas, realizadas a continuación en el texto principal o bien en una nota aparte o glosario y en el extremo opuesto, la integración de esta lengua en el texto circundante, como propone la crítica literaria Ch'ien (2005, a partir de Lindqvist). Mediante el empleo de esta última estrategia, la autora afirma que se consigue el efecto de situar las diferentes lenguas del texto en un mismo nivel, sin neutralizar una y llamar la atención sobre otra, señalando que se trata de algo distinto 5 .

La opción de señalización ortotipográfica mencionada, que en la literatura de adultos tiene lugar de forma sutil, mediante el empleo de letra cursiva o entrecomillado, recurre en la literatura infantil y juvenil, sin embargo, a procedimientos más variados y llamativos como el uso del color, el empleo de tipografía creativa o su integración en las imágenes que acompañan al texto. Así lo ilustra el ejemplo a continuación:

5. Algo que también expresa con otras palabras el escritor y académico J. Díaz en una entrevista concedida al Instituto de Estudios Dominicanos de la Universidad de la ciudad de Nueva York. En esta entrevista, el escritor reivindica poder escribir teniendo en mente como receptor principal a una audiencia bilingüe, en lugar de verse obligado a crear textos adaptados para el lector monolingüe mayoritario, el cual precisa indicaciones paratextuales explicativas sobre la segunda lengua para el correcto seguimiento del texto. "Siento que no soy un voyeur ni un informante nativo. No explico cosas culturales, con cursivas o con signos de exclamación, comentarios al margen o apartes. Fui agresivo acerca de eso porque tuve tantos modelos negativos, tantos escritores [...] que no están escribiendo para su propia gente. [...] The New Yorker me obligó a poner letra cursiva, pero después de eso estipulé como parte de mi contrato que si no aceptaban la ausencia de cursivas en los cuentos, sanseacabó: no pueden publicarlo" (D. Céspedes y S. Torres-Saillant, Fiction is the Poor Man's Cinema: An Interview with Junot Díaz, 2000, traducción adaptada a partir de Lorraine-Cresci 2017). 


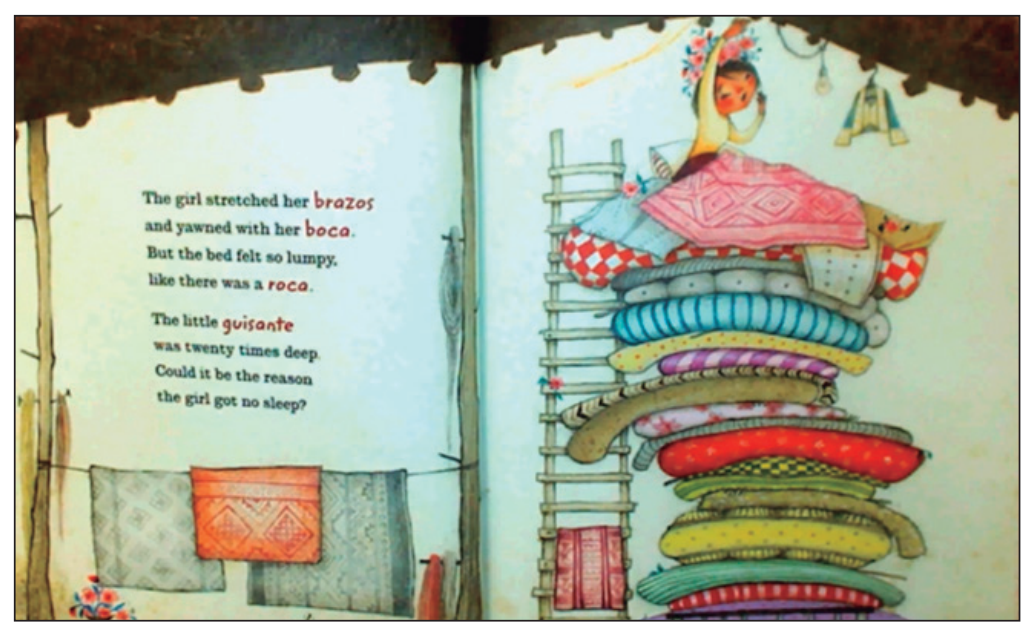

Imagen 1. Obra La princesa and the Pea (2017).

En el siguiente apartado, se presentan varias obras y autores de literatura infantil y juvenil que utilizan un multilingüismo de tipo intratextual translingüe.

\subsection{Algunos ejemplos de obras translingües en la literatura infantil y juvenil}

La escritura translingüe o multilingüismo intratextual, si bien se trata de un recurso poco convencional y que ha sido utilizado en obras literarias muy concretas, es patente que cuenta con cierto recorrido a lo largo de la historia de la literatura dirigida a un público adulto. Basta con mencionar la obra de figuras como William Shakespeare o Charlotte Brontë en el contexto literario inglés o de Thomas Mann y Emine Sevgi Özdamar, así como Victor Hugo y Fouad Laroui en los contextos literarios alemán y francés, respectivamente. Sin embargo, la utilización de la escritura translingüe en el ámbito de la LIJ ha tenido, si cabe, un carácter mucho más residual y escaso. Posiblemente debido a que, como argumenta la investigadora de LIJ, Shavit (2006), la principal norma que guía las traducciones dirigidas a niños y jóvenes, y en este caso asumimos que también su creación o escritura, es la aceptabilidad. Según la autora, estas obras se encuentran condicionadas por los dos requisitos siguientes: en primer lugar, "an adjustment of the text to make it appropriate and useful to the child, in accordance with what society regards as educationally good for the child" y en segundo lugar, "an adjustment of plot, characterization, and language to prevailing society's perceptions of the child's ability to read and comprehend" 
(Shavit 2006: 26). Cabría pensar, por tanto, que la escritura translingüe, la cual rompe con el estándar de monolingüismo preceptivo establecido por la norma gramatical, así como la mayor complejidad para la lectura que se le presupone a la mezcla de lenguas, se aleja bastante de lo que, en principio, constituiría un modelo de referencia apropiado para las capacidades y nivel de comprensión del niño y joven adulto.

No obstante, a pesar de la excepcionalidad referida, multilingüismo y translingüismo no son fenómenos ajenos a la LIJ. A continuación, se recogen algunos ejemplos de obras y autores que hacen uso de este recurso. En un primer grupo, se presentan aquellas obras que utilizan la alternancia entre lenguas con un enfoque eminentemente didáctico y en un segundo grupo, las obras que utilizan dicha alternancia con un enfoque más literario y de esparcimiento.

En primer lugar, encontramos las colecciones translingües de libros de lectura adaptados dirigidos a estudiantes de segundas lenguas. Estas obras se diseñan con un fin pedagógico. Las historias se narran mezclando las dos lenguas a nivel textual, de forma complementaria, de tal modo que los lectores lean algunas partes en su lengua materna y otras en la lengua extranjera que están adquiriendo. Asimismo, aunque no se mencione explícitamente, los personajes ficticios de estos libros tendrían la condición de bilingües, ya que, a pesar de hablar diferentes lenguas, se comprenden mutuamente. Dentro de esta categoría, el ámbito alemán cuenta con las colecciones siguientes en la combinación de lenguas alemán-inglés: I like you - und du? (1983) de E. O'Sullivan y D. Rösler, Marie, help me! (2007) de R. Ahrens, Hilfe - lost in London! (2007) de W. Hänel, Kommissar Schlotterteich (2010) de C. Tielmann o See you im nächsten Sommer (2006) de S. Schulz y D. Quinlan. El ámbito francés, por su parte, posee la colección Filou \& Pixie (2009) de P. D. Mellow en la combinación de lenguas francés-inglés con las obras The School Picture - La photo de classe, Our Best Clothes - Nos plus beaux habits, Crazy Cake - Un drôle de gateau. Asimismo, en la combinación lenguas francés-chino, se hallan los cuentos Le secret d'un prénom (2003) y Le voyage de Mao-Mi (2006) de la sinóloga francesa L. Bresner.

En segundo lugar, e iniciando el apartado de obras infantiles multilingües con un carácter más literario, encontramos la colección de novelas translingües sueco-alemán En ö i havet (1996) de A. Thor. La colección de libros documenta el envío de Steffi y Nelli, dos hijas de una familia austriaca de origen judío, a la costa sueca para protegerlas del avance del régimen nazi. Con el fin de mostrar 
las dificultades lingüísticas que encuentran las protagonistas a la hora de aprender sueco y poder comunicarse, palabras y frases en su alemán nativo se insertan en el texto primario en sueco.

En tercer lugar, y siguiendo con el grupo de obras de lectura de entretenimiento, dentro del ámbito peninsular, en la combinaciones de lenguas español-inglés y euskera-inglés, cabe mencionar la novela Dos letters, Bi letter (1990) del escritor B. Atxaga, la cual trata de un pastor de origen vasco Martín Aguirre u Old Martin, emigrado a los EE.UU., quien narra la historia de su vida de manera bilingüe, mezclando su idioma de origen con el del país en el que vive. Por su parte, dentro de la literatura hispana de Estados Unidos, hallamos el equivalente en el género infantil y juvenil de la literatura multilingüe producida para un público adulto, en la cual sus autores escriben alternando el idioma base del texto, el inglés, con frecuentes términos y frases en español. Algunos de estos títulos son: Abuela (1991) de A. Dorros, I love Saturdays y Domingos (1999) de A.F. Ada, Doña Flor (2005) de P. Mora, Mango, Abuela and me (2015) de M. Medina, La princesa and the Pea (2017) de S. Middleton o el cuento trilingüe, que además de inglés y español también incorpora el idioma polaco, The Subway Sparrow (1993) de L. Torres.

En cuarto y último lugar, cabe hacer mención a la novela infantil translingüe de origen portugués Céu Aberto de V. Castro e Almeida, que data del año 1907, siendo una de las obras pioneras en este ámbito. La obra presenta el viaje de tres niños de una familia acomodada que recorren Europa desde Portugal hasta Italia y Suiza, donde acuden a visitar unos internados escolares. En el texto, además de ser utilizado su idioma principal el portugués, también son empleados el inglés y el francés, junto a italiano, alemán y español.

\section{La investigación sobre la traducción de textos literarios y audiovisuales multilingües}

El fenómeno de la literatura multilingüe ha sido frecuentemente abordado en las últimas décadas en el campo de la investigación de literatura canónica para adultos y su traducción, dando lugar a notables estudios teóricos acerca de cómo el multilingüismo implicaba un replanteamiento del concepto tradicional de traducción (Cincotta 1996; Chan 2002; Lewis 2003; Pym 2004; Delabastita y Grutman 2005; Grutman 2006, 2012; Stratford 2008; Meylaerts 2006, 2013; Lennon 2015; Denti 2018). Asimismo, es creciente la publicación de estudios de caso específicos sobre autores y obras multilingües y su traducción a diversos 
idiomas. Muestra de ello son, entre otros, los trabajos The Brief Wondrous Life of Oscar Wao por Díaz (Boyden y Goethals 2011) y Pas pleurer por Salvayre (Montes-Villar 2017) en sus traducciones al español; The Lonely Londoners por Selvon (Buzelin 2006) e Hijo de Hombre por Roa Bastos (Suchet 2009) en sus traducciones al francés; Querido Diego por Poniatowska (Van Hecke 2017) en su traducción al neerlandés, Lolita por Nabokov (Vale de Gato 2018) en su traducción al portugués o trabajos que realizan un análisis múltiple de varias obras y combinaciones lingüísticas como el caso de Denti (2018).

De igual forma, el campo de la traducción audiovisual también se ha interesado por el estudio de este fenómeno. En este ámbito, existen algunos estudios metodológicos concretos sobre pautas para la traducción del multilingüismo como los de Heiss (2004), Bartoll (2006) o Corrius y Zabalbeascoa (2011), pero sobre todo se han llevado a cabo diversos estudios de caso sobre el doblaje y subtitulado de títulos audiovisuales multilingües. Dentro del análisis de películas, centrándose en el subtitulado, cabe mencionar: Spanglish en su subtitulado al español (Sanz Ortega 2011), Babel en su subtitulado al neerlandés (Van Hecke 2016) y La vita è bella y Tea with Mussolini en su doblaje y subtitulado original e inglés (Diadori 2003); por su parte, como estudios sobre doblaje, son reseñables: Close Encounters of the Third Kind en su doblaje al francés (Labate 2014), Inglorious Bastards en su doblaje a alemán y español (Voellmer y Zabalbeascoa 2014) y Butch Cassidy and the Sundance Kid (Corrius y Zabalbeascoa 2014), It's a Free World (De Higes 2014) y Vicky, Cristina, Barcelona (Díaz Cintas 2015) en su doblaje al español. En el contexto de un público infantil y juvenil cabe mencionar la investigación sobre la traducción para el doblaje de la L3 en películas de animación de Hurtado Malillos y Cuéllar Lázaro (2018).

Otros ejemplos, en este caso de estudios sobres series de TV son: Breaking Bad en su subtitulado original (Krämer y Duran Eppler 2018), Frasier en su doblaje a francés y español (Valdeón 2005), Fawlty towers y Allo, allo en su doblaje al español y catalán (Zabalbeascoa 2012) o Modern Family (Carbonell, Arnaiz-Uzquiza y Álvarez 2017) en su doblaje al español, francés e italiano.

Finalmente, el campo de los estudios de LIJ ha mostrado igualmente interés por el fenómeno multilingüe, especialmente por su aplicación y uso didáctico (Chappell y Faltis 2006; Eder 2009; Vázquez-García 2012; Kümmerling-Meibauer 2013a, 2013b; Hélot 2014); sin embargo, el estudio del proceso de traducción a otros idiomas de la presencia de esta característica en textos infantiles parece no haberse iniciado todavía. 


\section{Análisis comparativo de la traducción de los segmentos en L3. Interpretación de los resultados}

A continuación, en la parte aplicada de nuestro estudio, se analizará el caso práctico del tratamiento de la alternancia de código y las ocurrencias en L3 en la traducción alemana de la obra multilingüe Coco, contrastando las versiones textual $\mathrm{y}$ audiovisual del texto. Como se ha indicado previamente, el presente trabajo se propone estudiar la influencia de las variables destinatario y tipo de soporte en el proceso de traducción del fenómeno de la L3 y la alternancia de código. El estudio de estas relaciones se aborda desde la teoría semiótica de la unimodalidad y la multimodalidad (Anstey y Bull 2010, Martínez Sánchez 2012), tipología de clasificación textual que divide los textos en unimodales y multimodales. Según ésta, los textos unimodales son aquellos que utilizan un solo código o sistema semiótico: verbal, visual, auditivo, etc. y los textos multimodales, aquellos que combinan dos o más sistemas semióticos para la construcción de significado. De esta forma, por un lado, se analiza la traducción alemana del cuento infantil Coco (2017) como texto unimodal con un público objetivo de tipo infantil, obra que a su vez es comparada con la traducción alemana de In the time of the Butterflies (1994), obra multilingüe también unimodal pero dirigida a un público objetivo adulto. Por otro lado, se estudia y compara con las anteriores la traducción alemana de la película de animación Coco (2017), en sus modalidades de doblaje y subtitulado, como ejemplo de texto audiovisual multimodal.

La obra Coco, The Junior Novelization6 tiene un total de 137 páginas y presenta un promedio de una a dos ocurrencias en L3 español por cada página de texto en lengua base inglesa, una media de entre 12 y 15 ocurrencias por capítulo. Por otra parte, In the time of the butterflies, obra para adultos con la que se compara la obra infantil, mantiene esta misma tendencia con en torno a dos ocurrencias por página y una media de entre 17 y 20 ocurrencias por capítulo. De igual forma, su equivalente animado, la película Coco tiene una duración total de 105 minutos y presenta un promedio de, al menos, una ocurrencia en L3 español por cada minuto de video, un promedio de entre 30 y 40 ocurrencias en español por cada 30 minutos de película. Con el fin de ofrecer un estudio lo más completo y exhaustivo posible, hemos seguido el modelo de estudios previos sobre la traducción de obras multilingües de Humblé y De Wilder (2016) y hemos

6. El cálculo de la frecuencia de la L3 español en los diferentes textos y soportes se ha realizado mediante un procedimiento de muestreo aleatorio, en el que se han seleccionado en cada caso, dos capítulos y dos minutos de video al azar, se ha contabilizado el número de elementos en L3 presentes en cada uno de ellos y realizado la estimación de la tasa media de aparición. 
realizado una clasificación de las palabras y series de palabras en L3 halladas en el texto en función del campo léxico al que pertenecen. Las categorías con una mayor frecuencia de aparición son las siguientes: denominaciones de lugar, nombre de platos o alimentos, formas de saludo y agradecimiento, expresiones afirmativas y negativas, expresiones exclamativas y nombres propios.

Asimismo, para llevar a cabo el análisis de la parte multimodal de nuestro estudio, hemos aplicado el modelo de transcripción multimodal para productos audiovisuales propuesto por Thibault (2000) y Baldry (2000) y desarrollado posteriormente en el campo de la subtitulación por Taylor (2004) al proceso de traducción de la L3 en las modalidades de doblaje y subtitulado. El autor propone el uso del citado modelo para llevar a cabo de una forma sistemática el proceso de síntesis de la información en el subtitulado, dadas las limitaciones existentes de espacio y de capacidad de procesamiento por parte del público. De este modo, sería legítimo suprimir en el plano textual de los subtítulos aquella información que ya esté siendo transmitida de forma simultánea a través de otros canales semióticos. En el contexto de este trabajo en particular, se ha adaptado dicha hipótesis de trabajo a la posibilidad de transferir sin traducir, acompañados de una nueva lengua base, los términos en L3 de una obra multilingüe, ya sea en una nueva pista de audio o de forma escrita en los subtítulos ${ }^{7}$. Como fundamento de este enfoque, nos hemos basado en las tesis de trabajos previos como Karamitroglou (1998) en su propuesta de estándares comunes para el subtitulado europeo o MartínezBerenguer y Zabalbeascoa (2008). Se trata de dos autores que son partidarios de un tipo de traducción orientada hacia el polo extranjerizante, en la que los términos más populares de un idioma, así como aquellos deducibles por otros medios simultáneos, no deban ser necesariamente explicitados en la traducción: "Así pues, podríamos pensar que "las cosas fáciles" [...] no se subtitulan [...] Del mismo modo, $[\ldots]$ si ven que [alguien] dice algo en un idioma que no es L1 y a continuación se va, se sobreentiende que se debe haber despedido en su lengua [...]" (Martínez-Berenguer y Zabalbeascoa 2008: 8).

La sección a continuación presenta la discusión de algunos ejemplos representativos de la traducción del multilingüismo en los dos soportes, extraídos de las obras analizadas.

7. En lo que respecta específicamente al visionado con subtítulos de obras multilingües, la dualidad de canal de este medio (Díaz-Cintas 2003: 43) permite que el receptor siempre disponga de acceso a la pista de audio original en varias lenguas de la obra. No obstante, para los propósitos de nuestro análisis, sólo se valorará como reproducción del multilingüismo, aquellos casos en los que en el plano textual, el subtitulado realice también una traducción intralingüística o transcripción de los segmentos originales en L3 español, en lugar de una traducción interlingüística estándar L3-L2. 


\subsection{Denominaciones de lugar}

En el soporte unimodal, dentro de la categoría de denominaciones de lugar, encontramos los ejemplos de "plaza" y "hacienda". En el caso de la denominación "plaza", la estrategia de traducción por la que se opta es la "traducción con eco", esto es, la transferencia del término en L3 Español, incluyendo una traducción aclaratoria en $\mathrm{L}^{8}$ no presente en el original, "Plaza, dem belebten Platz". Asimismo, tienen lugar casos como el del término "hacienda" en los que el traductor opta por modificar o suprimir los segmentos en L3 en el original para salvar la dificultad que entraña lidiar con la propiedad del multilingüismo en la traducción. Así dicha categoría de lugar se traduce como "die unter ihnen lag" (situado debajo de ellos), omitiendo la referencia al término en segunda lengua. Las denominaciones de lugar de la obra para adultos "mercado" (ITB 1994: 198-199; DZS 2017: rec. elec.) y "colegio" (ITB 1994: 19; DZS 2017: rec. elec.) siguen por su parte asimismo una estrategia de transferencia simple de su forma en L3. En el soporte multimodal, encontramos de nuevo el ejemplo "Plaza". La posibilidad de percibir a través del canal visual el concepto abstracto universal de dicho espacio, reforzado al mismo tiempo por la información proporcionada por el canal de audio, hace posible que el espectador identifique la referencia y que la voz en off del film conserve este elemento en L3, "Willkommen auf der Plaza de la Cruz". No siendo así en el soporte unimodal en el que el término precisaba una traducción aclarativa en lengua principal. (Tabla 1).

\subsection{Nombres de platos o alimentos}

En el soporte unimodal, dentro de la categoría de nombres de platos o comidas, encontramos los ejemplos de "tamales" y "churros". Respecto al caso del término "tamales", en la primera ocurrencia del término, éste es transferido en su forma original en español, sin embargo, en su aparición en el texto por segunda vez es traducido mediante una paráfrasis explicativa ${ }^{9}$ que describe en qué

8. La estrategia de traducción con eco o estrategia de transferencia y traducción aclarativa alude al procedimiento de traducción por el cual un segmento en L3 en el texto origen es vertido a lengua meta mediante la repetición de la forma original de dicho segmento, yuxtapuesta a su equivalente traducido en L2. Este procedimiento también lo identifican los autores Richard y Kasparin (2014) bajo la denominación de redondance bilingue integrée. El alto número de ocurrencias en L3 español en el texto, sumado al hecho de que en la traducción de narrativa infantil se suela rechazar el uso de notas al pie o glosarios por creer que aumentan la dificultad del texto y hacen menos fluida la lectura (Arias 2003: 127), pueden haber determinado la implementación de esta opción.

9. El criterio de clasificación del resto de técnicas de traducción identificadas (generalización, amplificación o paráfrasis explicativa y descripción) se basa en la propuesta de Hurtado Albir (2001: 269-271). En este documento, puede consultarse una breve explicación de cada técnica. 
Tabla 1.1. Coco - Cuento multilingüe (Soporte unimodal)

\begin{tabular}{|c|c|}
\hline $\begin{array}{l}\text { As usual, Mariachi Plaza was full of } \\
\text { musicians strolling around, waiting } \\
\text { for their chance to serenade a couple } \\
\text { or a family with a love song or a } \\
\text { classic corrido. (Coco, The Junior } \\
\text { Novelization - CJN 2017: 5) }\end{array}$ & $\begin{array}{l}\text { Wie üblich gingen auf der Plaza, dem } \\
\text { belebten Platz, Mariachi-Musiker umher } \\
\text { und warteten auf eine Gelegenehit, einem } \\
\text { Pärchen ein Liebeslied oder einer Familie } \\
\text { eine Ballade vorzuspielen. (Coco, Das } \\
\text { Buch zum Film - CBF 2017: 11) }\end{array}$ \\
\hline $\begin{array}{l}\text { "You and I, we are artist, Miguel!" } \\
\text { [...] The world is our family!" He } \\
\text { gestured dramatically to the sparkling } \\
\text { city beyond his hilltop hacienda. (CJN } \\
\text { 2017: 95) }\end{array}$ & $\begin{array}{l}\text { "Du und ich, Miguel, wir sind Künstler! } \\
\text { [...] die ganze Welt ist unsere Familie!" } \\
\text { Ernesto zeigte mit dramatischer Geste zur } \\
\text { funkelnden Stadt, die unter ihnen lag. } \\
\text { (CBF 2017: 131) }\end{array}$ \\
\hline
\end{tabular}

Tabla 1.2. Coco - Película multilingüe (Soporte multimodal)

\begin{tabular}{|c|c|c|c|c|}
\hline \multirow[t]{2}{*}{ Min. } & \multirow{2}{*}{$\begin{array}{l}\text { Fotograma } \\
\text { (Imagen visual }+ \text { acción } \\
\text { cinética) }\end{array}$} & \multicolumn{2}{|c|}{ Pista de sonido } & \multirow{2}{*}{$\begin{array}{l}\text { Doblaje/ } \\
\text { Subtitulado TM }\end{array}$} \\
\hline & & $\begin{array}{l}\text { No verbal } \\
\text { (efectos } \\
\text { de sonido, } \\
\text { música) }\end{array}$ & $\begin{array}{l}\text { Verbal } \\
\text { (diálogo, } \\
\text { voz } \\
\text { narradora) }\end{array}$ & \\
\hline $\begin{array}{l}47: 15- \\
47: 40\end{array}$ & & $\begin{array}{l}\text { Sonido de la } \\
\text { campana del } \\
\text { tranvía. } \\
\text { Música y } \\
\text { bullicio de la } \\
\text { plaza. }\end{array}$ & $\begin{array}{l}\text { Términos } \\
\text { en L3: } \\
\text { "Plaza de } \\
\text { la Cruz". }\end{array}$ & $\begin{array}{l}\text { Viabilidad } \\
\text { transferencia L3 } \\
\text { TM } \\
\text { "Willkommen } \\
\text { auf der Plaza de } \\
\text { la Cruz" }\end{array}$ \\
\hline
\end{tabular}

consiste este plato tradicional mexicano, "Tamales", "dieser beliebten gefüllten Teigtaschen". Por su parte, la denominación del dulce "churro" en L3 en el texto origen es traducida utilizando un equivalente de la repostería de la cultura de llegada "Krapfen" (berlina). Los nombres de platos y comidas de In the Time of the Butterflies "dulce de leche" (ITB 1994: 234; DZS 2017: rec. elec.) y "limonada" (ITB 1994: 310; DZS 2017: rec. elec.) siguen en su caso una estrategia de transferencia simple de su forma en L3. En el soporte multimodal, se emplea de nuevo el término "tamales". En este caso, la información en imagen muestra qué aspecto tiene un tamal o empanadilla típica mexicana, por lo que dicho referente cultural puede conservarse. Puesto que este término tiene lugar en combinación con otras ocurrencias léxicas en L3, se ha considerado oportuno incluir su análisis en el apartado posterior de expresiones afirmativas y negativas. (Tabla 2). 
Tabla 2. Coco - Cuento multilingüe (Soporte unimodal)

\begin{tabular}{|l|l|}
\hline $\begin{array}{l}{[\ldots] \text { his abuelita, who ran their }} \\
\text { household with an iron fist. If Abuelita } \\
\text { said he needed to eat more tamales, } \\
\text { then Miguel ate more tamales. (CJN } \\
\text { 2017: 2-3) }\end{array}$ & $\begin{array}{l}{[\ldots] \text { seiner Abuelita, seiner Oma, die }} \\
\text { den Haushalt mit eiserner Hand regierte } \\
{[\ldots] \text {. Wenn seine Abuelita meinte, er }} \\
\text { müsste mehr Tamales essen, dann aß } \\
\text { Miguel mehr dieser beliebten gefüllten } \\
\text { Teigtaschen. (CBF 2017: 7-8) }\end{array}$ \\
\hline $\begin{array}{l}\text { "Welcome back! Anything to declare?" } \\
\text { an arrivals agent asked a skeleton. } \\
\text { "Some churros from my family," said } \\
\text { the traveler. (CJN 2017: 38-39) }\end{array}$ & $\begin{array}{l}\text { "Willkommen zurück! Haben Sie etwas } \\
\text { anzumelden?", fragte ein uniformiertes } \\
\text { Krelt hinter einem Schalter. "Ein paar } \\
\text { Reisende. (CBF 2017: 56) }\end{array}$ \\
\hline
\end{tabular}

\subsection{Formas de saludo y agradecimiento}

En el soporte unimodal, dentro de la categoría de formas de saludo y agradecimiento, encontramos las ocurrencias "Hola" y "Gracias". Estas formas en L3 son traducidas realizando la transferencia del término original acompañada de una traducción aclarativa en la lengua base o L2, "Hola, hallo", "Gracias, danke". Las formas de saludo y agradecimiento en In the Time of the Butterflies "Buenas" (ITB 1994: 173; DZS 2017: rec. elec.) y "Gracias" (ITB 1994: 134; DZS 2017: rec. elec.) siguen por su parte una estrategia de transferencia simple de su forma en L3. En este punto cabe señalar, que aquellos términos que se repiten con cierta frecuencia en la historia infantil escrita como "hola", "abuelita" o "Día de los Muertos" son traducidos en una primera ocurrencia mediante la estrategia conjunta de transferencia y posterior traducción aclarativa en lengua base; pero en posteriores ocasiones, dado que ya se ha proporcionado una vez su significado al lector y éste puede identificarlos, sólo se realiza la transferencia de los mismos, sin incluir de nuevo aclaraciones guía. Por su lado, en el soporte multimodal, encontramos de nuevo la forma de saludo "Hola". La información que recibimos a través del canal visual es que el personaje de Miguel entra a la habitación de la ofrenda, hace un gesto de saludo con la mano y da un beso en la mejilla a su bisabuela. Asimismo, a través del canal de audio, escuchamos el sonido del beso. Como la información de que se ha realizado un saludo ya nos la proporcionan otros canales semióticos, el cambio de código entre inglés y español y su equivalente alemán y español así como el empleo del término en L3 "Hola" pueden conservarse. Este término, en cambio, precisaba de una forma duplicada en el soporte unimodal. (Tabla 3). 
Tabla 3.1. Coco - Cuento multilingüe (Soporte unimodal)

\begin{tabular}{|l|l|}
\hline $\begin{array}{l}\text { Miguel kissed her cheek. "Hola, Mamá } \\
\text { Coco." (CJN 2017: 2) }\end{array}$ & $\begin{array}{l}\text { Miguel gab ihr einen Kuss auf die } \\
\text { Wange und sagte: "Hola, hallo, } \\
\text { Urgroßmutter Coco". (CBF 2017: 7) }\end{array}$ \\
\hline $\begin{array}{l}\text { "Enjoy the party, little músico!”. } \\
\text { "Gracias!" Miguel said. (CJN 2017: }\end{array}$ & $\begin{array}{l}\text { "Genieß die Party, kleiner Musiker!”. } \\
\text { "Gracias, danke”, sagte Miguel. (CBF } \\
\text { 2017: 122) }\end{array}$ \\
\hline
\end{tabular}

Tabla 3.2. Coco - Película multilingüe (Soporte multimodal)

\begin{tabular}{|c|c|c|c|c|}
\hline \multirow[t]{2}{*}{ Min. } & \multirow{2}{*}{$\begin{array}{l}\text { Fotograma } \\
\text { (Imagen visual }+ \text { acción } \\
\text { cinética) }\end{array}$} & \multicolumn{2}{|c|}{ Pista de sonido } & \multirow{2}{*}{$\begin{array}{l}\text { Doblaje/ } \\
\text { Subtitulado TM }\end{array}$} \\
\hline & & $\begin{array}{l}\text { No verbal } \\
\text { (efectos } \\
\text { de sonido, } \\
\text { música) }\end{array}$ & $\begin{array}{l}\text { Verbal } \\
\text { (diálogo, } \\
\text { voz } \\
\text { narradora) }\end{array}$ & \\
\hline 03:08 & & $\begin{array}{l}\text { Música } \\
\text { ambiental. } \\
\text { Sonido beso. }\end{array}$ & $\begin{array}{l}\text { Términos } \\
\text { en L3: } \\
\text { "Hola, } \\
\text { Mamá } \\
\text { Coco" }\end{array}$ & $\begin{array}{l}\text { Viabilidad } \\
\text { transferencia L3 } \\
\text { TM } \\
\text { "Hola, Mamá } \\
\text { Coco" }\end{array}$ \\
\hline
\end{tabular}

\subsection{Expresiones afirmativas y negativas}

En el soporte unimodal, dentro de la categoría de expresiones afirmativas y negativas, encontramos los casos "Sí" y "No". De nuevo, a la expresión afirmativa en L3 "Sí" le acompaña una traducción aclaratoria en alemán sobre la misma "Sí, ja". La expresión de negación "No" sigue, en cambio, un procedimiento homogeneizador de traducción estándar a lengua meta, sin ser diferenciada respecto al resto del contexto textual. Las expresiones afirmativas y negativas de la novela In the Time of the Butterflies "Sí, sí" (ITB 1994: 331; DZS 2017: rec. elec.) y "No" (ITB 1994: 85-86; DZS 2017: rec. elec.) siguen por su parte una estrategia de transferencia simple de su forma en L3. Finalmente, el tratamiento de las expresiones afirmativas y negativas en el soporte multimodal emplea un mecanismo análogo a los casos anteriores en este soporte. La secuencia presenta los resultados de traducción de expresiones de afirmación y negación, así como del nombre de un miembro de la familia. Los movimientos cinésicos en imagen muestran como el personaje de la abuela ofrece más comida a Miguel, que éste rechaza con un gesto negativo. Esto permite que el "no, gracias" en L3 español se mantenga. La abuela vuelve a insistir con voz de reproche y Miguel se ve forzado a decir que sí, lo que evidencian el tono 
con que responde y su sonrisa incómoda. A continuación, la abuela llena su plato, de lo que se infiere que el niño ha dado su aprobación. De nuevo, la respuesta afirmativa "sí" no necesitaría ser traducida. Asimismo, el canal visual nos muestra una señora de aspecto mayor, como evidencian su pelo canoso y arrugas, que abraza al personaje de Mamá Coco. Como estos datos permiten deducir al espectador del miembro de la familia de que se trata, la transferencia del término en español "Abuelita" está justificada. Además, el texto principal en alemán realiza posteriormente la aclaración "Meine Abuelita ist Uroma Cocos Tochter" que reafirma este supuesto. (Tabla 4).

Tabla 4.1. Coco - Cuento multilingüe (Soporte unimodal)

\begin{tabular}{|l|l|}
\hline $\begin{array}{l}\text { "In the courtyard, m'ijos," she said to } \\
\text { Papá and Tío Berto. "You want it down } \\
\text { by the kitchen" Papá asked. "Sí. Eh... } \\
\text { next to the other one," she answered. } \\
\text { (CJN 2017: 19) }\end{array}$ & $\begin{array}{l}\text { "In den Hof damit", sagte Abuelita zu } \\
\text { Küche haben?", fragte Miguels Papá. "Sí, } \\
\text { ja, stellt ihn neben den anderen." (CBF } \\
\text { 2017: 30) }\end{array}$ \\
$\begin{array}{l}\text { "No, no, no, chamaco, you are loco if } \\
\text { you think -“ Hector began. (CJN 2017: } \\
\text { 65) }\end{array}$ & $\begin{array}{l}\text { "Nee, nee, nee, Junge, du bist verrückt, } \\
\text { wenn du glaubst...", fing Hector an zu } \\
\text { protestieren. (CBF 2017: 92) }\end{array}$ \\
\hline
\end{tabular}

Tabla 4.2. Coco - Película multilingüe (Soporte multimodal)

\begin{tabular}{|c|c|c|c|c|}
\hline \multirow[t]{2}{*}{ Min. } & \multirow{2}{*}{$\begin{array}{l}\text { Fotograma (Imagen } \\
\text { visual }+ \text { acción cinética) }\end{array}$} & \multicolumn{2}{|c|}{ Pista de sonido } & \multirow{2}{*}{$\begin{array}{l}\text { Doblaje/ } \\
\text { Subtitulado TM }\end{array}$} \\
\hline & & $\begin{array}{l}\text { No verbal } \\
\text { (efectos } \\
\text { de sonido, } \\
\text { música) }\end{array}$ & $\begin{array}{l}\text { Verbal } \\
\text { (diálogo, voz } \\
\text { narradora) }\end{array}$ & \\
\hline $\begin{array}{l}03: 50- \\
03: 54\end{array}$ & & $\begin{array}{l}\text { Tono de } \\
\text { reproche } \\
\text { en la } \\
\text { intervención } \\
\text { de la abuela. } \\
\text { Respuesta } \\
\text { tono forzado } \\
\text { de Miguel. }\end{array}$ & $\begin{array}{l}\text { Términos en } \\
\text { L3: "Abuelita". } \\
\text { Aclaración } \\
\text { posterior en } \\
\text { L1: "Meine } \\
\text { Abuelita ist } \\
\text { Uroma Cocos } \\
\text { Tochter" } \\
\text { L3: "No, } \\
\text { gracias". } \\
\text { L3: "Sí,", } \\
\text { "Tamales". } \\
\text { Aclaración } \\
\text { posterior en } \\
\text { L1: "Ich wusste } \\
\text { doch, dass du } \\
\text { das sagst". }\end{array}$ & $\begin{array}{l}\text { Viabilidad } \\
\text { transferencia L3 } \\
\text { TM } \\
\text { "NA: Meine } \\
\text { Abuelita ist } \\
\text { Uroma Cocos } \\
\text { Tochter./ Du } \\
\text { bist so ein } \\
\text { Spargel, m'ijo. } \\
\text { Nimm, noch } \\
\text { ein paar./ No, } \\
\text { gracias. /Ich } \\
\text { habe gefragt } \\
\text { ob du noch ein } \\
\text { paar Tamales } \\
\text { willst. /Sí? / } \\
\text { Ich wusste } \\
\text { doch, dass du } \\
\text { sagst" }\end{array}$ \\
\hline
\end{tabular}




\subsection{Expresiones exclamativas}

En el soporte unimodal, dentro del campo de las expresiones exclamativas, se hallan los ejemplos "Vámonos", "Llévelo" y "Ayúdame". En el caso de la expresión "Vámonos", se aplica también la solución de traducción de la utilización del término en segundo idioma con la adición de una traducción aclaratoria en la lengua meta, quedando convertida en "Vámonos, los, kommt!". Asimismo, los segmentos en L3 también son sometidos a alteraciones o supresiones con el objetivo de eliminar la restricción del multilingüismo y simplificar el proceso de traducción. Así, la expresión de incentivo de compra en L3 "Llévelo" queda transformada en el texto de llegada en un adjetivo calificativo para la prenda en venta "Tolle T-shirts!" (excelentes camisetas). En otros casos, la forma interpelativa en L3 es directamente eludida en la traducción. La petición de auxilio "Security! Ayúdame!" que tiene lugar en el fragmento de la persecución durante la actuación de Ernesto de la Cruz, queda suprimida en el texto de llegada alemán. Respecto a las expresiones exclamativas de la obra para adultos "Exactamente" (ITB 1994: 4; DZS 2017: rec. elec.), “Ay, Dios mío" y "Epa” (ITB 1994: 287; DZS 2017: rec. elec.), estas son transferidas aisladamente en su caso en la forma original. Por último, en el soporte multimodal, encontramos de nuevo el ejemplo de la expresión exclamativa "Vámonos". En la secuencia, el personaje de la abuela reprende a Miguel por sus intenciones de ausentarse durante la celebración del Día de Muertos, indicándole que se trata de una tradición y que ese día debe hacer el esfuerzo de estar presente. El uso del término en L3 "Vámonos" y el posterior movimiento cinésico en pantalla poniendo la mano en la espalda de su nieto y conduciéndolo a otra estancia de la casa, permite concluir al espectador el sentido de la expresión, empleada para apremiar a alguien a moverse o dirigirse hacia algún lugar. (Tabla 5).

\subsection{Nombres propios}

En el soporte unimodal, dentro de la categoría de nombres propios, hallamos los casos "Poco Loco", "De la Cruzcito", y "Frida Kahlo". Los nombres del título de la canción y el apodo del protagonista presentan una forma duplicada en su versión traducida, figurando como sigue: "Poco Loco, ein bisschen verrückt", "De la Cruzcito, der kleine de la Cruz". Por su parte, en el caso de la referencia a un personaje célebre de la cultura origen, "Frida Kahlo", se considera pertinente añadir una especificación 
Tabla 5.1. Coco - Cuento multilingüe (Soporte unimodal)

\begin{tabular}{|c|c|}
\hline $\begin{array}{l}\text { "If Mamá Imelda can’t come to us-" } \\
\text { began Tía Rosita. "Then WE are } \\
\text { going to HER!"” exclaimed Papá Julio. } \\
\text { "Vámonos!". (CJN 2017: 35) }\end{array}$ & $\begin{array}{l}\text { "Wenn Ururgroßmutter Imelda nicht zu uns } \\
\text { kommen kann...", begann Tante Rosita. } \\
\text { [...] "Dann gehen WIR zu IHR", setzte } \\
\text { Urgroßvater Julio den Satz fort. "Vámonos, } \\
\text { los, kommt!". (CBF 2017: 51) }\end{array}$ \\
\hline $\begin{array}{l}\text { Miguel looked around the plaza. It } \\
\text { glowed and hummed with the shouts of } \\
\text { vendors selling a variety of crafts and } \\
\text { treats to passersby. "Llevelo! T-shirts!" } \\
\text { called a vendor selling Ernesto de la } \\
\text { Cruz souvenirs. (CJN 2017: 74) }\end{array}$ & $\begin{array}{l}\text { Miguel sah sich um. Überall auf der Plaza } \\
\text { verkauften Händler ihre Waren. "Tolle } \\
\text { T-shirts!” rief ein Händler, der Ernesto-de- } \\
\text { la-Cruz-Souvenirs verkaufte. (CBF 2017: } \\
\text { 103) }\end{array}$ \\
\hline $\begin{array}{l}\text { Ernesto turned to run. "After him!" } \\
\text { Mamá Imelda yelled. [...] "Security! } \\
\text { Ayúdame!" The Rivera family fanned } \\
\text { out after him. (CJN 2017: 116) }\end{array}$ & $\begin{array}{l}\text { Ernesto rannte davon. "Ihm nach!”, rief } \\
\text { Ururgroßmutter Imelda. [...] * Die ganze } \\
\text { Familie Rivera jagte ihm nach. (CBF 2017: } \\
160)\end{array}$ \\
\hline
\end{tabular}

Tabla 5.2. Coco - Película multilingüe (Soporte multimodal)

\begin{tabular}{|c|c|c|c|c|}
\hline \multirow[t]{2}{*}{ Min. } & \multirow{2}{*}{$\begin{array}{l}\text { Fotograma } \\
\text { (Imagen visual }+ \text { acción } \\
\text { cinética) }\end{array}$} & \multicolumn{2}{|c|}{ Pista de sonido } & \multirow{2}{*}{$\begin{array}{l}\text { Doblaje/ } \\
\text { Subtitulado } \\
\text { TM }\end{array}$} \\
\hline & & $\begin{array}{l}\text { No verbal } \\
\text { (efectos } \\
\text { de sonido, } \\
\text { música) }\end{array}$ & $\begin{array}{l}\text { Verbal } \\
\text { (diálogo, voz } \\
\text { narradora) }\end{array}$ & \\
\hline $\begin{array}{l}09: 38- \\
10: 21\end{array}$ & $x^{n} \frac{1}{4}$ & $\begin{array}{l}\text { La abuela } \\
\text { alza la } \\
\text { voz en la } \\
\text { exclamación } \\
\text { para hacer } \\
\text { énfasis en } \\
\text { el mensaje } \\
\text { transmitido. } \\
\text { Suspiro de } \\
\text { resignación } \\
\text { de Miguel. }\end{array}$ & $\begin{array}{l}\text { Términos en } \\
\text { L3: "Ofrenda", } \\
\text { "¡Vámonos!”. }\end{array}$ & $\begin{array}{l}\text { Viabilidad } \\
\text { transferencia } \\
\text { L3 TM } \\
\text { "Und jetzt } \\
\text { zur Ofrenda. } \\
\text { ¡Vámonos!” }\end{array}$ \\
\hline
\end{tabular}

descriptiva sobre esta figura y el motivo de su reconocimiento no presente en el texto original. Por su lado, los nombres propios de la obra In the Time of the Butterflies "Jaimito" y "Pedrito" (ITB 1994: 90; DZS 2017: rec. elec.) siguen una estrategia de transferencia simple en su forma en L3. Asimismo, la denominación de lugar "Ojo de Agua” (ITB 1994: 116; DZS 2017: rec. elec.) 
que ya incluye una aclaración suplementaria en $\mathrm{L} 1^{10}$ en el texto original sobre el significado del nombre utilizado, es mantenida en la versión traducida. En ultimo lugar, en el soporte multimodal, hallamos el caso del nombre propio "Miguelititito". Con el propósito de reconducir la inclinación de Miguel por dedicarse a la profesión artística, los padres y abuela de Miguel deciden otorgarle un puesto como trabajador en el taller familiar de fabricación de calzado. El gesto cinético de agarrar a alguien de los carrillos que muestra la imagen, combinado con la expresión de orgullo del rostro de la abuela y su posterior abrazo proporciona indicios al espectador de que lo enunciado simultáneamente a través del canal de audio "Miguelititito", vocablo en el cual además se repite el mismo sonido agudo en su parte final, se trata de una forma de referirse cariñosamente a alguien. Esto permite la conservación del término en L3 como "Oh, unser Miguelititito führt die Familientradition weiter" sin que sea necesario agregar una traducción aclarativa consecutiva. (Tabla 6).

Tabla 6.1. Coco - Cuento multilingüe (Soporte unimodal)

\begin{tabular}{|c|c|}
\hline $\begin{array}{l}\text { "“What about...” Miguel thought hard. } \\
\text { "'Poco Loco'?" "Okay! Now you're } \\
\text { talking!” A stagehand approached } \\
\text { Miguel. "De la Cruzcito?" he asked. } \\
\text { Miguel nodded at his stage name. } \\
\text { "You're on standby" (CJN 2017: 75) }\end{array}$ & $\begin{array}{l}\text { "Wie wär's mit... 'Poco Loco, ein } \\
\text { bisschen verrückt'?" “Okay! Das trifft's!" } \\
\text { Ein Bühnenhelfer kam zu ihnen. "De la } \\
\text { Cruzcito?” Miguel nickte. Jetzt hatte er } \\
\text { einen Bühnennamen, de la Cruzcito, der } \\
\text { kleine de la Cruz. "Halt dich bereit." } \\
\text { (CBF 2017: 105) }\end{array}$ \\
\hline $\begin{array}{l}\text { A woman dressed in a colourful frock, } \\
\text { with flowers pinned in her hair and a } \\
\text { dark unibrow above her eyes, stepped } \\
\text { up. "Yes, it is I. Frida Kahlo," the } \\
\text { artist said, pointing gracefully at } \\
\text { herself. "Famouse Mexican icon, } \\
\text { beloved of the people. Shall we skip } \\
\text { the scanner? (CJN 2017: 40) }\end{array}$ & $\begin{array}{l}\text { Ein Frauenskelett trat an den Schalter, es } \\
\text { trug bunte lange Röcke, Blumen im Haar } \\
\text { und hatte eine schwarze, durchgehende } \\
\text { Augenbraue, unter Kennern Monobraue } \\
\text { gennant. "Ja, ich bin es selbst. Frida } \\
\text { Kahlo, die berühmte, weltberühmte } \\
\text { Malerin", tällerte es und deutete huldvoll } \\
\text { auf sich. "Die mexikanische Legende, } \\
\text { Liebling des Volkes. Können wir das mit } \\
\text { dem Scanner nicht einfach auslassen? (CBF } \\
\text { 2017: 58) }\end{array}$ \\
\hline
\end{tabular}

10. Como apunta Cuéllar Lázaro (2014: 364) los nombres propios a veces requieren traducción para que el lector comprenda matices o comentarios acerca de su significado realizados en el texto. Cfr. asimismo Cuéllar Lázaro (2016) para la problemática de su traducción en un contexto audiovisual. 
¡EH, TÚ! ¿POR QUÉ ME TRADUCES CON ECO? LA TRADUCCIÓN DEL MULTILINGÜISMO...

Tabla 6.2. Coco - Película multilingüe (Soporte multimodal)

\begin{tabular}{|c|c|c|c|c|}
\hline \multirow[b]{2}{*}{ Min. } & \multirow[b]{2}{*}{$\begin{array}{l}\text { Fotograma (Imagen } \\
\text { visual + acción cinética) }\end{array}$} & \multicolumn{2}{|c|}{ Pista de sonido } & \multirow[b]{2}{*}{$\begin{array}{l}\text { Doblaje/Subtitulado } \\
\text { TM }\end{array}$} \\
\hline & & $\begin{array}{l}\text { No verbal } \\
\text { (efectos } \\
\text { de sonido, } \\
\text { música) }\end{array}$ & $\begin{array}{l}\text { Verbal } \\
\text { (diálogo, voz } \\
\text { narradora) }\end{array}$ & \\
\hline $\begin{array}{l}14: 52- \\
15: 46\end{array}$ & & $\begin{array}{l}\text { Música } \\
\text { ambiental. }\end{array}$ & $\begin{array}{l}\text { Términos en } \\
\text { L3: "Migue- } \\
\text { litititito". }\end{array}$ & $\begin{array}{l}\text { Viabilidad } \\
\text { transferencia L3 } \\
\text { TM } \\
\text { "Unser } \\
\text { Miguelititito führt } \\
\text { die Familien- } \\
\text { tradition weiter" } \\
\text { SU: "Unser } \\
\text { Miguelito..." }\end{array}$ \\
\hline
\end{tabular}

\section{Conclusiones}

Los ejemplos proporcionados ofrecen una muestra resumida de los mecanismos desarrollados por el traductor a la hora de afrontar la traducción de textos con heterogeneidad lingüística, tanto en su vertiente literaria, traductor de literatura infantil o literatura para adultos, como en su vertiente audiovisual. Las tres clases de textos analizados tienen en común que el propósito o finalidad que se ha primado en la traducción ha sido la conservación de los segmentos en L3, con el objetivo de brindar en la lengua del público receptor de la traducción una experiencia de lectura o visionado híbridos, similar a los que experimentaría el lector o espectador de las obras originales. Sin embargo, los medios utilizados para realizar esta conservación varían en cada caso, en función de las características formales de cada tipo de traducción. El análisis y diagrama a continuación sintetizan cómo se relacionan y distribuyen las opciones de traducción disponibles para segmentos en L3 en función de las variables analizadas de soporte y público.

En la traducción para un soporte audiovisual y la traducción textual para un público adulto, dado, por un lado, el apoyo de otros canales semióticos a la hora de transmitir la información de manera simultánea y, por otro, la capacidad de procesamiento y experiencia vital que se le presupone a un lector adulto, hacen que en estos dos tipos de soporte predomine la estrategia de transferencia singularizada del elemento en L3 en la lengua original, en la práctica totalidad 


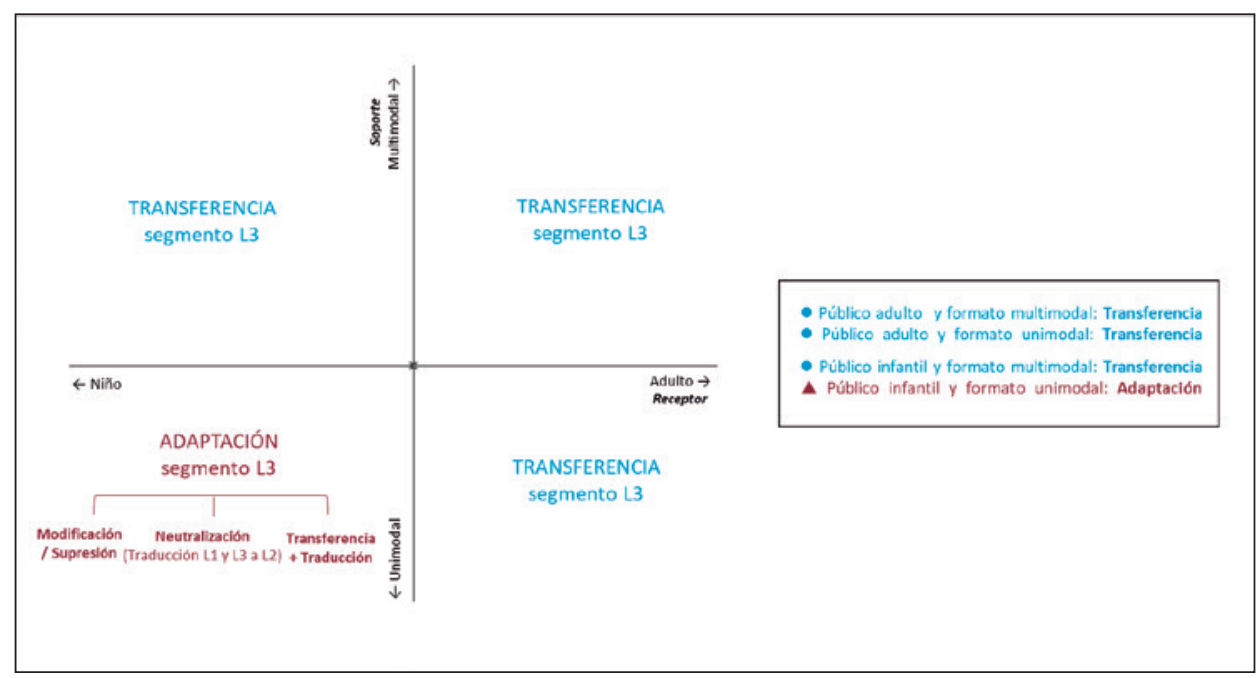

Imagen 2. Gráfico en el que se representa la influencia de las variables soporte y receptor en la selección de estrategias de tratamiento de la L3.

de las ocurrencias. En cambio, en la traducción para un soporte textual dirigido a un público infantil, dado el tipo de receptor y la unicidad de canales existente, la variedad de estrategias utilizadas es mucho más compleja. Si bien, la técnica de transferencia es también la más frecuentemente utilizada, ésta siempre va acompañada, al menos en la primera aparición de cada término, de una glosa intratextual o traducción aclarativa añadida en lengua principal, lo que coloquialmente hemos denominado en el título del trabajo como "traducir con eco". Otro tipo de estrategias identificadas han sido la modificación o supresión del segmento en L3 o la neutralización del elemento mediante su traducción a L2 por medio de un término equivalente o paráfrasis. Asimismo, en la traducción para este tipo de soporte, se ha podido evidenciar en algunos casos el impacto transfigurador del estilo y expresión original del autor que producen las comunes traducciones a L2, perífrasis y creaciones autónomas en lugares en los que el texto original mantiene una ocurrencia en L3.

Todo ello nos permite concluir que la variable soporte (texto escrito, escrito con ilustraciones o audiovisual) al que se va a realizar la traducción, así como la variable destinatario (receptor infantil o adulto), aunque en principio puedan considerarse poco significativas, resultan dos factores determinantes en el resultado de la traducción, especialmente en el caso de que ésta presente la propiedad multilingüe. 


\section{Fuentes literarias y audiovisuales analizadas}

ÁlVAREZ, J. (1994). In the Time of the Butterflies. Chapel Hill, N.C.: Algonquin Books.

ÁLVAREZ, J. (2017). Die Zeit der Schmetterlinge (In the Time of the Butterflies). Traducido al alemán por Carina von Enzenberg y Hartmut Zahn. Múnich: Piper ebooks.

CERVANTES, Á. (2017). Coco. The Junior Novelization. Nueva York: Random House.

CERVANTES, Á. (2017). Coco. Das Buch zum Film (Coco. The Junior Novelization). Traducido al alemán por Anke Albrecht. Berlin: Ravensburger. Coco. Lee Unkrich. Anthony Gonzalez. Walt Disney Studios Motion Pictures, 2017. Film. DVD.

Coco. Lee Unkrich. Anthony Gonzalez. Walt Disney Studios Motion Pictures, 2017. Film. Versiones doblada y subtitulada al alemán del Servicio de Películas de la plataforma Youtube.

\section{Bibliografía}

ADA, A. F. (2002). I Love Saturdays y Domingos. New York: Atheneum Books.

AHRENS, R. (2007). Marie, help me! Berlin: Rowohlt Taschenbuch Verlag.

ALVSTAD, C. (2010). "Children's literature and translation" en Handbook of Translation Studies. (Eds. Y. Gambier y L. van Doorslaer). Ámsterdam y Filadelfia: John Benjamins: 22-27.

ANSTEY, M. y BULL, G. (2010). "Helping teachers to explore multimodal texts". Curriculum and Leadership Journal 8 (16).

ARIAS TORRES, J. P. (2003). "Mercado y traducción: Naguim Mahfuz para niños" en Traducción y literatura infantil (Coords. I. Pascua et al.). Las Palmas de Gran Canaria: Anaga: 117-132.

ATXAGA, B. (1992). Dos letters /Bi letter. Bilbao: Ediciones B.

BALDRY, A. (2000). "English in a visual society: comparative and historical dimensions in multimodality and multimediality" en Multimodality and Multimediality in the distance learning age. (Ed. A. Baldry). Campobasso: Palladino Editore: 41-90.

BARTOLL, E. (2006). "Subtitling multilingual films" en MuTra - Audiovisual translation scenarios (Eds. M. Carroll, H. Gerzymisch-Arbogast y S. Nauert). Conference Proceedings: 14-18. 
BOYDEN, M. y GOETHALS, P. (2011). "Translating the watcher's voice: Junot Díaz's The brief wondrous life of Oscar Wao into Spanish". Meta: Journal des traducteurs 56 (1): 20-41.

BRESNER, L. (2003). Le secret d'un prénom. Arles: Actes Sud Junior.

BRESNER, L. (2006). Le voyage de Mao-Mi. Arles: Actes Sud Junior.

BUZELIN, H. (2006). "Traduire l'hybridité littéraire: Réflexions à partir du roman de Samuel Selvon : The Lonely Londoners". Target 18 (1): 91-119.

CARBONELL-GALINDO, J., ARNÁIZ-UZQUIZA, V. y ÁLVAREZ-ÁLVAREZ, S. (2017). "Caleidoscopio multilingüe: productos audiovisuales multilingües presentados en diferentes escenarios de doblaje. El caso de Modern Family". Actas de la conferencia TRAFILM: 33-34.

CASTRO E ALMEIDA, V. (1907). Céu Aberto. Lisboa: Clássica Editora.

CÉSPEDES, D. y TORRES-SAILLANT, S. (2000). "Fiction is the Poor Man's Cinema: An Interview with Junot Díaz". Callaloo 23 (3): 892-907.

CH'IEN, E. N. M. (2005). Weird English. Cambridge: Harvard UP.

CHAN, L. T. (2002). "Translating bilinguality: Theorizing translation in the postbabelian era". The Translator 8 (1): 49-72.

CHAPPELL, S. y FALTIS, C. (2006). "Bilingualism, Spanglish, culture and identity in Latino children's literature". Children's Literature in Education 38 (4): 253-262.

CHAUME VARELA, F. (2003). Doblatge i subtitulació per a la TV. Barcelona: Eumo.

CINCOTTA, M. (1996). Naturalising Linguistic Aliens: The Translation of Codeswitching. Conference on Interpreting and Translation. Sydney: University of Western Sydney.

CORRIUS GIMBERT, M. y ZABALBEASCOA TERRÁN, P. (2011). "Language variation in source texts and their translations. The case of L3 in film translation". Target 23 (1): 113-130.

CORRIUS GIMBERT, M. y ZABALBEASCOA TERRÁN, P. (2014). "How Spanish in an American film is rendered in translation: dubbing Butch Cassidy and the Sundance Kid in Spain". Perspectives: Studies in Translation 22 (2): 255-270.

CUÉLlAR LÁZARO, C. (2014). "Los nombres propios y su tratamiento en traducción". Meta: Journal des traducteurs 59 (2): 208-220.

CUÉLLAR LÁZARO, C. (2016). "Proper Names in Audiovisual Translation. Dubbing vs. Subtitling". Journal of Onomastics 107/108: 117-134.

DE HIGES ANDINO, I. (2014). "The translation of multilingual films: Modes, strategies, constraints and manipulation in the Spanish translations of It's a 
¡EH, TÚ! ¿POR QUÉ ME TRADUCES CON ECO? LA TRADUCCIÓN DEL MULTILINGÜISMO...

Free World...". Linguistica Antverpiensia, New Series 13: 211-231.

DELABASTITA, D. y GRUTMAN, R. (2005). "Introduction. Fictional representations of multilingualism and translation" en Fictionalising Translation and Multilingualism (Eds. D. Delabastita y R. Grutman). Linguistica Antverpiensia 4: 11-34.

DENTI, C. (2018). "L'hétérolinguisme ou penser autrement la traduction". Meta 62 (3): 521-537.

DIADORI, P. (2003). "Doppiaggio, sottotitoli e fenomeni di code-switching e code-mixing: La traduzione dei testi mistilingui”. Italica 80 (4): 529-541.

DÍAZ-CINTAS, J. (2003). Teoría y práctica de la subtitulación. Barcelona: Ariel. DÍAZ-CINTAS, J. (2015). "Multilingüismo, traducción audiovisual y estereotipos: el caso de Vicky, Cristina,Barcelona". Prosopopeya: Traducción, ideología y poder en la ficción audiovisual 9: 135-161.

DORROS, A. (1997). Abuela. New York: Puffin Books.

EDER, U. (2009). Mehrsprachige Kinder - und Jugendliteratur für Mehrsprachige Lernkontexte. Wien: Praesens.

FLORES, N. y GARCÍA, O. (2013). "Linguistic third spaces in education: Teachers' translanguaging across the bilingual continuum" en Managing diversity in education: Languages, policies, pedagogies (Eds. D. Little et al.). Bristol: Multilingual Matters: 243-256.

GARCÍA DE TORO, C. (2013). "Los viajes de Pinocchio. Sus primeras andanzas en España”. Sendébar 24: 291-306.

GARCÍA DE TORO, C. (2014). "Traducir literatura para niños: de la teoría a la práctica”. TRANS. Revista de Traductología 18 (1): 123-137.

GRUTMAN, R. (2006). "Refraction and recognition: Literary multilingualism in translation". Target 18 (1): 17-47.

GRUTMAN, R. (2012). "Traduire l'hétérolinguisme: questions conceptuelles et (con)textuelles" en Autour d'O. Senior: hétérolinguisme et traduction (Ed. M. A. Montout). Angers: Université d'Angers.

HÄNEL, W. (2007). Hilfe - lost in London! Berlin: Rowohlt Taschenbuch Verlag. HEISS, C. (2004). "Dubbing Multilingual Films: A New Challenge?". Meta 49 (1): $208-220$.

HÉLOT, C. (2014). "Rethinking bilingual pedagogy in Alsace: Translingual writers and translanguaging" en Heteroglossia as practice and pedagogy. (Eds. A. Blackledge y A. Creese). New York: Springer: 1-20.

HIRIART, B. (2004). Escribir para niñas y niños. México: Paidós.

HUMBLÉ, P. y DE WILDER, L. (2016). "The Translation of Multilingual Literature in a Migrant World. The Case of Junot Diaz" en Folia Linguistica et 
Litteraria. (Eds. T. Phillips y M. Krivokapić). Nikšić: Institute for Language and Literature, University of Montenegro: 157-169.

HUNT, P. (1990). Children's Literature: The Development of Criticism. Nueva York: Routledge.

HURTADO ALBIR, A. (2001). Traducción y traductología. Madrid: Cátedra.

HURTADO MALILLOS, L. y CUÉLLAR LÁZARO, C. (2018). "The Treatment of Multilingualism in Audiovisual Translation: The Case of Children's and Young People's Animated Films". Skopos 9: 123-152.

JIMÉNEZ CARRA, N. (2011). "La traducción del cambio de código inglésespañol en la obra The Brief Wondrous Life of Oscar Wao de Junot Díaz". Sendebar 22:159-180.

JIMÉNEZ, S. (7 Dic. 2017). "Cervantes strives for realistic portrayal of Latinos in novels". Two Worlds, Dos Mundos. El Periódico Bilingüe para la Comunidad Hispana de Kansas City. http://dosmundos.com/webpress/2017/12/07/ cervantes-strives-realistic-portrayal-latinos-novels/

KARAMITROGLOU, F. (1998). "A Proposed Set of Subtitling Standards in Europe". Translation Journal 2 (2).

KRÄMER, M. y DURAN-EPPLER, E. (2018). "The Deliberate Non-Subtitling of L3s in Breaking Bad: A Reception Study". Meta 63 (2): 365-391.

KREMNITZ, G. (2004). Mehrsprachigkeit in der Literatur. Wie Autoren ihre Sprachen wählen. Viena: Praesens.

KÜMMERLING-MEIBAUER, B. (2013a). "Code-Switching in Multilingual Picturebooks". Bookbird 51 (3): 12-21. http://doi.org/10.1353/bkb.2013.0042.

KÜMMERLING-MEIBAUER, B. (Ed.) (2013b). "Multilingualism and Children's Literature". Bookbird 51 (3): IV-X. http://doi.org/10.1353/bkb.2013.0064.

LABATE, S. (2014). "Translating French into French: The case of Close Encounters of the Third Kind". Linguistica Antverpiensia, New Series 13: 193-210.

LENNON, B. (2010). In Babel's Shadow: Multilingual Literatures, Monolingual States. Minneapolis: University of Minnesota Press.

LENNON, B. (2015). "Challenges to Monolingual National Literatures" en The Multilingual Challenge: Cross-Disciplinary Perspectives. (Eds. C.J. Kramsch y U. Jessner-Schmid). Berlin: De Gruyter Mouton: 143-160.

LEWIS, R. A. (2003). "Langue métissée et traduction: quelques enjeux théoriques". Meta: Journal des traducteurs 48 (3): 411-420.

LORRAINE-CRESCI, K. (2017). "“Call it my revenge on English': 'Negocios' de Junot Díaz y sus traducciones disonantes". Literatura: teoría, historia, crítica 19 (2): 147-181. 
¡EH, TÚ! ¿POR QUÉ ME TRADUCES CON ECO? LA TRADUCCIÓN DEL MULTILINGÜISMO...

MARTÍ FERRIOL, J. L. (2013). El método de traducción. Doblaje y subtitulación frente a frente. Castellón de la Plana: Publicaciones de la Universitat Jaume I.

MARTÍNEZ-BERENGUER, N. y ZABALBEASCOA TERRÁN, P. (2008). La subtitulación de una película multilingüe Ladies in Lavender. Barcelona: Universitat Pompeu Fabra.

MARTÍNEZ SÁNCHEZ, J. J. (2012). "Géneros del discurso digital: escritura y sociedad". Actas del IV Congreso Iberoamericano de las Lenguas en la Educación y la Cultura. Salamanca: OEI.

MEDINA, M. (2015). Mango, Abuela and me. Massachusetts: Candlewick Press. MELLOW, P. D. (2009). Filou \& Pixie. Vincennes: Talents hauts.

MEYLAERTS, R. (2006). "Heterolingualism in/and Translation: How Legitimate Are the Other and His/Her Language? An Introduction". Target 18 (1): $1-15$.

MEYLAERTS, R. (2013). "Multilingualism as a challenge for translation studies" en Routledge Handbook of Translation Studies. (Eds. C. Millán-Varela y F. Bartrina). Londres: Routledge: 519-533.

MIDDLETON, S. (2017). La Princesa and the Pea. New York: G.P. Putnam's Sons.

MONTES-VILLAR, L. (2017). "Traduire l'hétérolinguisme dans les textes de 1'exil: code-switching et fragnol dans Pas pleurer de Lydie Salvayre". Revue Hispanismes 2: 254-262.

MORA, P. (2005). Doña Flor. New York: Knopf.

O'SULLIVAN, E. (2013). "Children's Literature and translation studies" en The Routledge Handbook of Translation Studies. (Eds. C. Millán-Varela y F. Bartrina). Nueva York: Routledge: 451-463.

O'SULLIVAN, E. y RÖSLER, D. (1983). I like you - und du? Berlin: Rowohlt Taschenbuch.

OITTINEN, R. (2000). Translating for Children. Nueva York: Garland Publishing. PYM, A. (2004). "On the Pragmatics of Translating Multilingual Texts". JoSTrans 30: 40-65.

RICHARD, C. y KASPARIAN, S. (2014). "Formes et fonctions des alternances de langues dans les romans contemporains hétérolingues au Canada". Revue de l'Université de Moncton 45: 127-148.

SANZ ORTEGA, E. (2011). "Subtitling and the relevance of non-verbal information in polyglot films". New Voices in Translation Studies 7: 19-34.

SCHULZ, S. y QUINLAN, D. (2006). See You, Im Nächsten Sommer. Berlin: Rowohlt. 
SHAVIT, Z. (1994). "Beyond the Restrictive Frameworks of the Past: Semiotics of Children's Literature - A New Perspective" en Kinderliteratur im Interkulturellen Prozess. (Eds. H. H. Ewers, G. Lehnert y E. O'Sullivan). Stuttgart y Weimar: Verlag J. B. Metzler: 3-15.

SHAVIT, Z. (2006). "Translation of Children's Literature" en The Translation of Children's Literature: A Reader. (Ed. G. Lathey). Clevedon: Multilingual Matters: 25-40.

SIPE, L. R. (2011). "The Art of the Picturebook" en Handbook of Research in Children's and Young Adult Literature (Eds. S.A. Wolf et al.). New York: Routledge: 238-252.

STRATFORD, M. (2008). "Autour de Babel! Les défis multiples du multilinguisme". Meta: Journal des traducteurs 53: 457-470.

SUCHET, M. (2009). "Translating literary heterolingualism: Hijo de hombre's French variations" en Translating research projects 2. (Eds. A. Pym y A. Perekrestenko). Tarragona: Intercultural Studies Group, Universitat Rovira i Virgili: 151-164.

TAYLOR, C. (2004). "Multimodal Text Analysis and Subtitling" en Perspectives on Multimodality. (Eds. Ventola, E., Cassily, C. y M. Kaltenbacher). Amsterdam: John Benjamins: 153-172.

THIBAULT, P. (2000). "The multimodal transcription of a television advertisement: theory and practice" en Multimodality and Multimediality in the distance learning age. (Ed. A. Baldry). Campobasso: Palladino Editore: 311-385.

THOR, A. (2003). En ö i havet. Stockholm: Bonnier Carlsen.

TIELMANN, C. (2002). Kommissar Schlotterteich. Hamburg: Carlsen.

TORRES, L. (1997). The Subway Sparrow. New York: Square Fish.

UGWU, R. (19 Nov. 2017). "How Pixar Made Sure 'Coco' Was Culturally Conscious". New York Times. https://www.nytimes.com/2017/11/19/movies/ coco-pixar-politics.html.

VALDEÓN GARCÍA, R. (2005). "Asymmetric representations of languages in contact: uses and translations of French and Spanish in Frasier". Linguistica Antverpiensia 4: 279-294.

VALE DE GATO, M. (2018). "Lolita's Love Affair with the English Language: Heterolingualism and Voice in Translation". Meta 63 (2): 322-341.

VAN HECKE, A. (2016). "Multilingüismo y Subtitulación: La (in)comunicación en Babel". Foro Hispánico 51: 137-156.

VAN HECKE, A. (2017). "La Traducción De Una Novela Multilingüe: 'Querido Diego, Te Abraza Quiela’ De Elena Poniatowska”. Romaneske 1: 6-11. 
VÁZQUEZ GARCÍA, C. (2012). "Literatura infantil hispana: identidad fronteriza" en Literatura para a Infância e Juventude. (Eds. B. Rodríguez y S. Reis da Silva). Vigo/Braga: ANILIJ: 623-633.

VOELLMER, E. y ZABALBEASCOA TERRÁN, P. (2014). "How multilingual can a dubbed film be? Language combinations and national traditions as determining factors". Linguistica Antverpiensia, New Series 13: 232-250.

WILSON, R. (2011). "Cultural Mediation through Translingual Narrative". Target 23 (2): 235-250.

ZABALBEASCOA TERRÁN, P. (2000). "Contenidos para adultos en el género infantil: El caso del doblaje de Walt Disney" en Literatura infantil y juvenil: Tendencias actuales en investigación (Eds. V. Ruzicka, C. Vázquez y L. Lorenzo). Vigo: Universidade de Vigo, 19-30.

ZABALBEASCOA TERRÁN, P. (2012). "Translating heterolingual audiovisual humor. Beyond the blinkers of traditional thinking" en The Limits of Literary Translation (Eds. J. Muñoz-Basols, C. Fouto, L. Soler y T. Fisher). Kassel: Reichenberger: 317-338. 